\title{
Case Report: Longitudinal assessment of a COVID-19 patient in the midst of a pandemic [version 1; peer review: 1
}

\section{approved, 1 approved with reservations]}

\author{
Rashid A. Chotani1-4, Syed S. Ashraf33, Fatima Aziz33, Shakeel M. Thakurdas (iD) 5 , \\ Afham Chotani (iD6, Alize Ashraf7, Khurram Nasir ${ }^{8}$, M. Rizwan Sohail9, \\ Faisal H. Cheema (iD) $5,10,11$ \\ ${ }^{1}$ University of Nebraska Medical Center, Omaha, NE, USA \\ ${ }^{2}$ IEM, Morrisville, NC, USA \\ ${ }^{3}$ CareLife Medical, Fairfax, VA, USA \\ ${ }^{4}$ Washington Vascular Specialists, Takoma Park, MD, USA

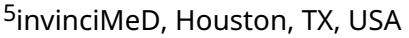 \\ ${ }^{6}$ Lake Erie College of Osteopathic Medicine, Erie, PA, USA \\ ${ }^{7}$ Langley High School, Mclean, VA, USA \\ ${ }^{8}$ Houston Methodist DeBakey Heart and Vascular Center, Houston, TX, USA \\ ${ }^{9}$ Mayo Clinic, Rochester, MN, USA \\ ${ }^{10}$ HCA Research Institute, Nashville, TN, USA \\ ${ }^{11}$ University of Houston College of Medicine, Houston, TX, USA
}

V1 First published: 11 Aug 2020, 9:972

https://doi.org/10.12688/f1000research.24911.1

Latest published: 11 Aug 2020, 9:972

https://doi.org/10.12688/f1000research.24911.1

\section{Abstract}

Directional clinical evaluation and management of coronavirus disease (Covid-19) was initially presumptive based on the Wuhan data set as reported by World Health Organization (WHO). The current recommendations emanate primarily from the Chinese experience and subsequent Centers for Disease Control and Prevention (CDC) guidelines. Here we report a case with an "atypical" patient risk profile and variant longitudinal disease progression contrasting from existing recommendations. Our case report suggests that a universal 14-day quarantine timeline may not be sufficient; that correlation is needed between viral presence as determined by RT-PCR and a patient's humoral response tested by serologic immunoassay of IgM \& IgG. Hence, a clinical decision-making algorithm that can help clinicians clear a patient from "active infection" status would require testing that is sufficiently reliable, and should include serological testing for immunity.

\section{Keywords}

COVID-19, Coronavirus, Pandemic, Pneumonia, SARS, Respiratory, Throat swab

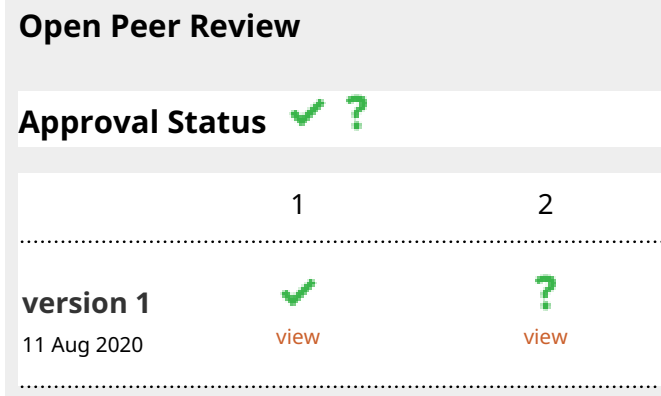

1. Ya-Dong Gao iD, Zhongnan Hospital of Wuhan University, Wuhan, China

Xiang Dong, Zhongnan hospital of Wuhan University, Wuhan, China

2. José López Castro ID, Monforte Public Hospital, Lugo, Spain

Any reports and responses or comments on the article can be found at the end of the article. 
This article is included in the Coronavirus

collection.

Corresponding author: Faisal H. Cheema (faisal.cheema@me.com)

Author roles: Chotani RA: Conceptualization, Data Curation, Formal Analysis, Investigation, Methodology, Project Administration, Writing - Original Draft Preparation, Writing - Review \& Editing; Ashraf SS: Conceptualization, Data Curation, Formal Analysis, Investigation, Methodology, Project Administration, Writing - Original Draft Preparation, Writing - Review \& Editing; Aziz F: Conceptualization, Data Curation, Formal Analysis, Investigation, Methodology, Project Administration, Writing - Original Draft Preparation, Writing - Review \& Editing; Thakurdas SM: Data Curation, Writing - Original Draft Preparation, Writing - Review \& Editing; Chotani A: Data Curation, Formal Analysis, Investigation, Methodology, Project Administration, Writing - Original Draft Preparation, Writing - Review \& Editing; Ashraf A: Data Curation, Formal Analysis, Investigation, Methodology, Project Administration, Writing Original Draft Preparation, Writing - Review \& Editing; Nasir K: Validation, Writing - Review \& Editing; Sohail MR: Validation, Writing Review \& Editing; Cheema FH: Conceptualization, Data Curation, Writing - Original Draft Preparation, Writing - Review \& Editing

Competing interests: No competing interests were disclosed.

Grant information: The author(s) declared that no grants were involved in supporting this work.

Copyright: $\odot 2020$ Chotani RA et al. This is an open access article distributed under the terms of the Creative Commons Attribution License, which permits unrestricted use, distribution, and reproduction in any medium, provided the original work is properly cited.

How to cite this article: Chotani RA, Ashraf SS, Aziz F et al. Case Report: Longitudinal assessment of a COVID-19 patient in the midst of a pandemic [version 1; peer review: 1 approved, 1 approved with reservations] F1000Research 2020, 9:972

https://doi.org/10.12688/f1000research.24911.1

First published: 11 Aug 2020, 9:972 https://doi.org/10.12688/f1000research.24911.1 


\section{Background}

Coronavirus disease 2019 (COVID-19) is a highly contagious viral pandemic caused by a novel strain of severe acute respiratory syndrome (SARS)-related coronavirus (CoV) named SARS-CoV-2 ${ }^{1}$. The virus is part of the family of coronaviruses which have been involved in previous infectious outbreaks, namely SARS 2003 and Middle East respiratory syndrome (MERS) 2012 ${ }^{2}$. Initially detected in December 2019 in the Hubei Province of $\mathrm{China}^{3}$, information related to its epidemiology and virulence is constantly evolving as the disease spreads across the world. Overall global prevalence of the disease is difficult to assess with reasonable accuracy due to a paucity of standardized global testing and reporting ${ }^{4}$, which in turn makes it difficult to accurately assess the mortality rate associated with the disease.

As of June 17, 2020, confirmed cases of COVID-19 are close to $8,200,000$ with more than 444,000 deaths reported worldwide. The United States has become the epicenter of this pandemic with more than 2,137,000 confirmed cases and over 116,000 reported deaths ${ }^{5}$. The information related to Covid-19 is evolving on a daily basis and recent reports indicate that there may be other Covid-19 strains affecting different areas of the globe ${ }^{6}$.

\section{Objective}

To describe the longitudinal assessment of a 50-year-old female, RT-PCR confirmed - COVID-19 patient, during an evolving pandemic and changing guidelines.

\section{Clinical vignette}

We present the case report of a 50-year-old South Asian female who came to our clinic in the middle of April 2020, complaining of intermittent fever ranging between $100-102^{\circ} \mathrm{F}$, chills, night sweats, fatigue, and myalgia for the past six days. The patient reported no past medical history, no recent international travel history or exposure to any known COVID-19 positive patient and is a nutritionist by profession. At the clinic (day 6 of symptom onset, see Figure 1), she was noted to have a fever of $100.2^{\circ} \mathrm{F}$. Two days prior (day 4 of symptoms, Figure 1), she reported testing negative for Streptococcus (group A strep) and influenza at an urgent care facility. During her visit at our clinic, her physical exam was unremarkable and her lungs were clear on auscultation. In view of her clinical presentation and negative strep and influenza test, we decided to test her for COVID-19 and an oropharyngeal swab was collected and sent for RT-PCR analysis. One day after her visit to our clinic (day 7 of symptoms, Figure 1), the patient developed shortness of breath (SOB) with persistent fever ranging between $100-102^{\circ} \mathrm{F}$, chills, night sweats, fatigue and myalgia. She was started on a seven-day course of Levaquin $(500 \mathrm{mg}$ once daily) empirically for a presumptive diagnosis of community acquired pneumonia while awaiting RT-PCR results and albuterol inhaler (every four hours or as needed) for bronchospastic cough. The following day (day 8 of symptoms, Figure 1), she returned to the clinic, and during auscultation of the lungs, bibasilar crackles were noted, greater on her left lung compared to the right lung. She was then sent to the

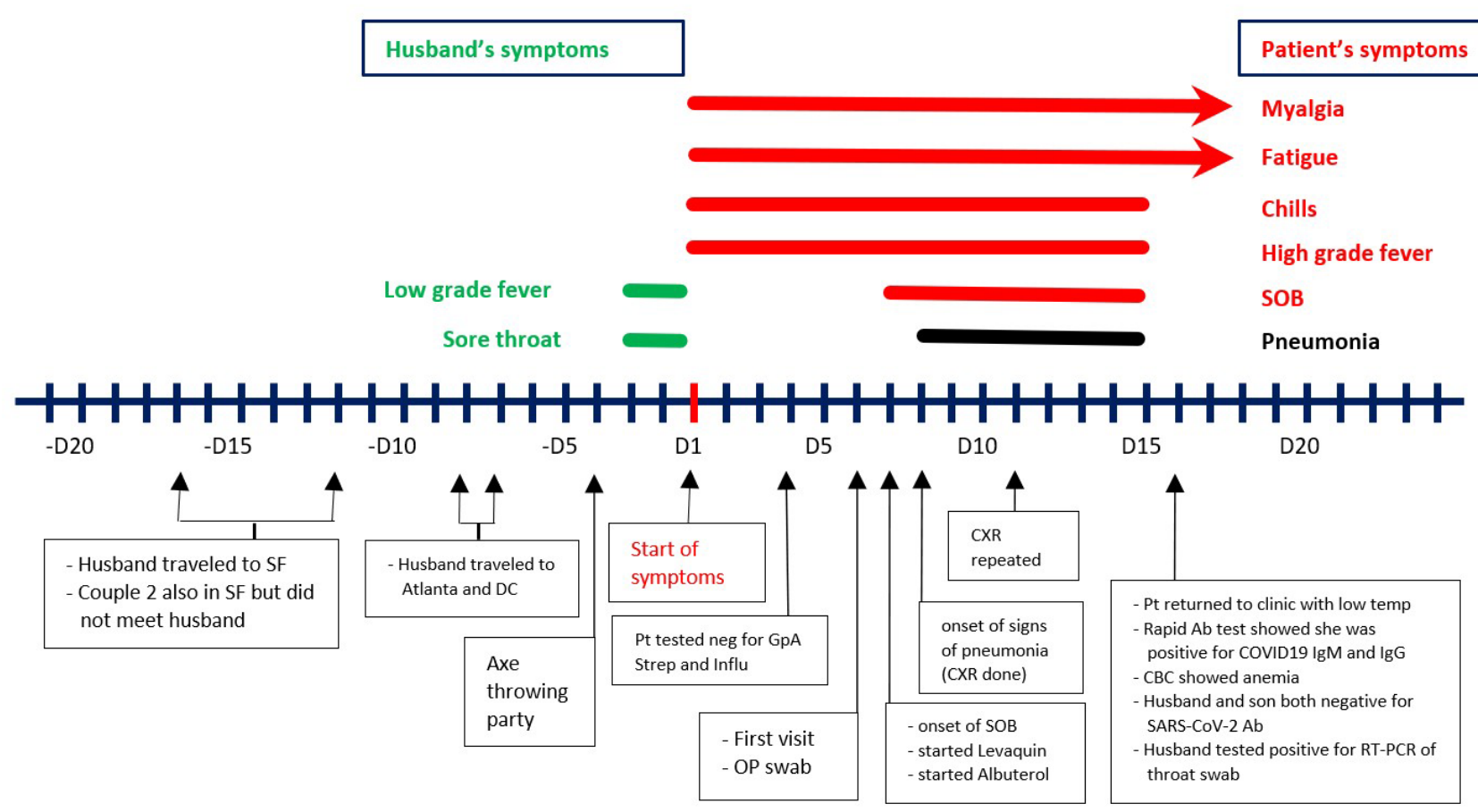

Figure 1. Timeline of the patient's symptoms and important events. A graphic representation of some of the relevant events with respect to the day of symptom onset shown as D1 (red bar on the timeline). Even though pneumonia is not a symptom we thought it would be helpful to easily visualize the onset of signs of pneumonia on the timeline. At no point was the patient hospitalized perhaps because the $\mathrm{O}_{2}$ saturation remained at or above 97\%. SF, San Francisco; Pt, patient; GpA Strep, Group A Streptococcus; Influ, influenza; OP, oropharyngeal; CXR, chest $\mathrm{x}$-ray; SOB, shortness of breath; $\mathrm{Ab}$, antibody; CBC, complete blood count. 
emergency department (ED) of a nearby hospital where a chest $\mathrm{x}$-ray was performed on the same day (Figure 2). The chest $\mathrm{x}$-ray revealed bilateral pulmonary infiltrates. Her laboratory work-up in the ED showed an elevated blood lactate level of $2.0 \mathrm{mmol} / \mathrm{L}$ (normal: $0.5-1 \mathrm{mmol} / \mathrm{L}$ ), while her complete blood count and basic metabolic panel showed no abnormalities. Oxygen saturation rate was $97 \%$ and she was subsequently discharged to home. Three days after her visit to the ED (day 11 of symptoms, Figure 1), the patient still reported persistent SOB and was sent by our clinic to the ED for follow-up evaluation and possible need for chest CT given concerns for Covid-19 related viral pneumonia. At the ED, another chest x-ray was done which showed patchy opacities with air bronchograms in the left mid-lung and left lower lobe as well as similar patchy peripheral opacities at the right upper lobe, suggesting infectious etiology and worsening pneumonia (Figure 3). Oxygen saturation rate was still $97 \%$, no other laboratory tests were reportedly done during this visit and she was again

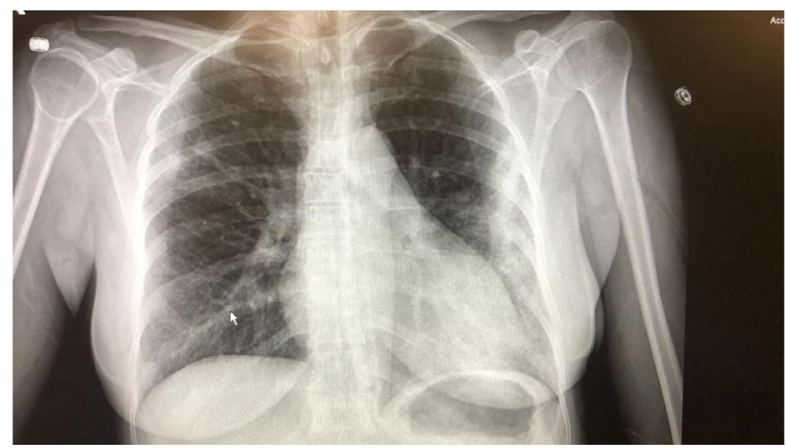

Figure 2. Chest x-ray of the patient done on day 7 from symptom onset. The patient returned to the clinic one day after the onset of shortness of breath and was referred to the emergency department of a nearby hospital where this $\mathrm{x}$-ray was done. The $\mathrm{x}$-ray shows patchy bilateral opacities, left greater than right, concerning for pneumonia.

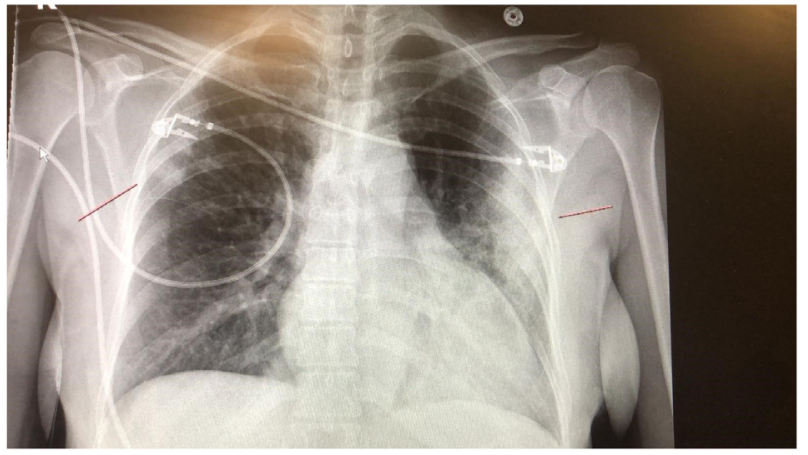

Figure 3. Chest $\mathrm{x}$-ray of the patient done on day 11 from symptom onset. The $\mathrm{x}$-ray shows patchy opacities with air bronchograms in the left mid-lung and left lower lobe as well as similar patchy peripheral opacities at the right upper lobe suspicious for infectious etiology which appears mildly worsened. discharged to home. Four days later (day 15 of symptoms, Figure 1), the patient became afebrile $\left(97.6^{\circ} \mathrm{F}\right)$ and reported not having any chills but still complained of significant fatigue and myalgia; her SOB, however, was improving. The next day (day 16 of symptoms, Figure 1), the patient returned to our clinic with a fever of $99.1^{\circ} \mathrm{F}$. While her breathing was much better, she stated that she felt weak and had significant diffuse muscle pain. At the clinic, we performed a rapid COVID-19 specific IgM/IgG test, provided by Boston Biopharma, which came up positive for both $\operatorname{IgM}$ and $\operatorname{IgG} 16$ days after the initial onset of symptoms (Figure 1). Routine labs were also done that showed anemia with hemoglobin $10.5 \mathrm{~g} / \mathrm{dl}$ (normal: $11.7-15.5 \mathrm{~g} / \mathrm{dl}$ ) and hematocrit $33.1 \%$ (normal: $35-45 \%$ ) with mean corpuscular volume $74 \mathrm{fl}$ (normal: 80-100fl), mean corpuscular hemoglobin 23.5pg (normal: 27-33pg), mean corpuscular hemoglobin concentration $31.7 \mathrm{~g} / \mathrm{dl}$ (normal: $32-36 \mathrm{~g} / \mathrm{dl}$ ), platelet count $857,000 / \mathrm{ml} \quad(140-400 \mathrm{~K} / \mathrm{ml})$, an elevated C-reactive protein level (CRP) of $30.4 \mathrm{mg} / \mathrm{l}$ (normal: $<8.0$ ), and creatine phosphokinase $(\mathrm{CPK})$ of $39 \mathrm{u} / \mathrm{L}$ (normal: 29-143 u/L). Her comprehensive metabolic panel (CMP), and white blood cell count with differential showed no abnormalities. On day 17 since symptom onset, the patient was afebrile $\left(97.5^{\circ} \mathrm{F}\right)$ without dyspnea and no further labs were done after this point since the patient started to improve symptomatically. She did however complain of persistent weakness and myalgia. The patient's husband and son had both remained asymptomatic during the entire episode and both tested negative with Boston Biopharma's rapid COVID-19 antibody test on the same day as the patient was tested for antibodies (day 16 of patient's symptoms, Figure 1). However, results from nasopharyngeal swabs taken from both the husband and son for RT-PCR analysis returned a week later were positive for the husband only. The husband's repeat IgM and IgG, checked twice seven days apart, remain negative and he has continued to remain asymptomatic.

All three individuals, the patient, her husband, and her son were interviewed again for any recollection of recent travel or secondary exposure. Her husband had returned just two weeks before the onset of her symptoms, after a week-long stay in San Francisco. Four days after his return from San Francisco, he travelled again to Atlanta for a day trip and attended a conference in Washington, DC before returning home the next day. Just a couple of days after the husband's return the patient recalled going to an axe-throwing party with him and a group of friends. She also claimed that her husband developed a slight fever and a sore throat the day after this party and his symptoms lasted for at least three days (see Figure 1). Of note, the patient herself had developed a sore throat and low-grade fever by this time and this was the onset of all her reported symptoms. We also learned that four people from the group that attended the axe-throwing party reported "some" illness. One couple (Couple 1) had high fever and cough that lasted for 2-3 days and were told to self-quarantine for 14 days by their primary care provider (no information is available if they were tested). Couple 2 had been in San Francisco the same week as patient's husband, but they did not meet there. This couple also reported being sick with fever and cough that lasted 
three days around the same time as her husband's symptoms. They were also advised by their primary care physician to self-quarantine for 14 days. All cases from the axe-throwing party (husband, Couple 1 and Couple 2) recovered without any worsening of symptoms in 2-3 days, and prior to the patient's development of her symptoms.

\section{Discussion}

The most common symptoms of Covid-19 are fever, cough, loss of energy or exhaustion, and to a varying degree, other bodily manifestations ${ }^{7}$. The symptoms and findings suggestive of disease progression that should raise concern are chest discomfort (pressure, tightness) ${ }^{8}$, confusion or change in mental status not otherwise related to another etiology ${ }^{9}$, and hypoxia without necessarily experiencing shortness of breath ${ }^{10}$. In more severe cases, infection can cause pneumonia, severe acute respiratory distress syndrome (ARDS), and even death. It is believed that ARDS and similar catastrophic respiratory changes may be related to a cytokine storm phenomenon ${ }^{11}$. The period within which the symptoms seem to manifest is wide, ranging from two to 14 days $^{12}$. In our patient, a 50-year-old female with no international travel history, no co-morbidities but with potential exposure to multiple people who had traveled to a high Covid-19 exposure area, initial symptoms (fever, sore throat, chills, myalgia), appeared on the third day after being at the axe throwing party (a potential exposure event) and progressed in little over a week to dyspnea and worsening bilateral pneumonia. The husband, Couple 1 and Couple 2 seemed to have developed mild symptoms just a day or two after the axe-throwing party, suggesting that one of the members at this party was the source and probably an asymptomatic carrier. It is important to note that our patient who was Covid-19 positive (RT-PCR), developed bilateral pneumonia and was treated only with Levaquin and albuterol and recovered, indicating that in the absence of some major event such as a cytokine storm or ARDS, viral pneumonia due to SARS CoV-2 can clear by itself.

It is well established that the initial defense to a foreign antigen involves a complex immune response, both of innate and adaptive types. Antibody response in the form of $\operatorname{IgM}$ provides a critical defense during the early stages of a viral infection. Subsequent development of a longer-term IgG antibodies further augments the adaptive immune response and may eventually represent some form of immunological memory ${ }^{13}$. In our patient, both $\operatorname{IgM}$ and $\operatorname{IgG}$ were positive 16 days after symptom onset. Testing of Covid-19 $\operatorname{IgM}$ and $\operatorname{IgG}$ antibodies is therefore an effective method for confirming whether an individual has had the Covid-19 infection. This has value both in diagnosis and monitoring for early or late infectivity response. While viral replication usually wanes within a week or two without significant illness in most healthy individuals, antibody response, especially $\mathrm{IgG}$ antibody, typically rises for a few weeks after exposure and can remain elevated for long periods of time, sometimes even years, which is in fact the driving principle behind vaccination. For this reason, antibody testing will likely be the most valuable tool to assess the prevalence of SARS-CoV-2 infection and the level of exposure within the population ${ }^{14}$.

A recent study published in the Lancet concluded that RT-PCR alone may not be sufficient in diagnosing a patient with Covid-19 in the lower respiratory tract or in assessing infectivity after few weeks of exposure ${ }^{15}$. Another study raises concern for the high false negative rates associated with nasopharyngeal and oropharyngeal swab sampling in an out-patient setting ${ }^{16}$. In view of these findings, it is our opinion that rapid antibody testing is an important tool for the clinical assessment and management of Covid-19. Such a test would be ideal in the third week from symptom onset based on our current knowledge of the immune response to viral pathogens. Subsequent RT-PCR is warranted if $\operatorname{IgM}$ is found to be positive so that the patient may be fully assessed for continued viral infectiousness and possible isolation. Additionally, given the asymptomatic status of both husband and son in such proximity to a Covid-19 patient, a rapid antibody test can be valuable for determining a person's Covid-19 disease status and for surveillance ${ }^{17}$. In this case, the patient's spouse tested positive with nasopharyngeal RT-PCR but negative with repeated serologic tests raising the possibility that he may be a nasal carrier.

Our patient also had elevated CPK levels with persistent weakness and myalgia suggestive of post-viral myopathy. A broader survey of COVID-19 patients can inform if this is a significant sequela of the disease.

\section{Conclusion}

This case report helps to highlight the urgent need to answer some of the most pertinent questions associated with this pandemic such as the duration of quarantine, role of serologic antibody tests in diagnosing, management, and immunity assessment, and the role of various laboratory measurements in clinical follow-up. We recognize the limitations of this being a single case report (and of associated family members) and acknowledge that additional studies are necessary to determine how best to screen RT-PCR positive patients to assure that they are no longer infectious to their immediate contacts as well as the healthcare workers who are providing care for them ${ }^{18}$.

\section{Data availability}

All data underlying the results are available as part of the article and no additional source data are required.

\section{Consent}

Written informed consent for publication of their clinical details and clinical images was obtained from the patient. Written informed consent was also obtained from the mentioned relatives of the patient for publication of their clinical details.

\section{Acknowledgement}

We thank Dr. Sadiya Naseem, DNP, FNP-BC for following up on the patient and helping collect information 
1. Coronaviridae Study Group of the International Committee on Taxonomy of Viruses: The species Severe acute respiratory syndrome-related coronavirus: classifying 2019-nCoV and naming it SARS-CoV-2. Nat Microbiol. 2020; 5(4): 536-544.

PubMed Abstract | Publisher Full Text | Free Full Text

2. Peeri NC, Shrestha N, Rahman MS, et al.: The SARS, MERS and novel coronavirus (COVID-19) epidemics, the newest and biggest global health threats: what lessons have we learned? Int J Epidemiol. 2020; dyaa033. PubMed Abstract | Publisher Full Text | Free Full Text

3. Huang C, Wang Y, Li X, et al:: Clinical features of patients infected with 2019 novel coronavirus in Wuhan, China. Lancet. 2020; 395(10223): 497-506. PubMed Abstract | Publisher Full Text | Free Full Text

4. Haffajee RL, Mello MM: Thinking Globally, Acting Locally - The U.S. Response to Covid-19. N Engl J Med. 2020; 382(22): e75.

PubMed Abstract | Publisher Full Text

5. Johns Hopkins Coronavirus Resource. Reference Source

6. Weise E: $\mathbf{8}$ strains of the coronavirus are circling the globe. Here's what clues they're giving scientists. Yahoo! news. 2020.

Reference Source

7. Wang D, Hu B, Hu C, et al: Clinical Characteristics of 138 Hospitalized Patients with 2019 Novel Coronavirus-Infected Pneumonia in Wuhan, China. JAMA. 2020; 323(11): 1061-1069.

PubMed Abstract | Publisher Full Text | Free Full Text

8. Inciardi RM, Lupi L, Zaccone G, et al:: Cardiac Involvement in a Patient with Coronavirus Disease 2019 (COVID-19). JAMA Cardiol. 2020; 5(7): 1-6. PubMed Abstract | Publisher Full Text | Free Full Text

9. Filatov A, Sharma P, Hindi F, et al:: Neurological Complications of Coronavirus
Disease (COVID-19): Encephalopathy. Cureus. 2020; 12(3): e7352. PubMed Abstract | Publisher Full Text | Free Full Text

10. Report of the WHO-China Joint Mission on Coronavirus Disease 2019 (COVID-19). 2020 Reference Source

11. Mehta P, McAuley DF, Brown M, et al: CoVID-19: consider cytokine storm syndromes and immunosuppression. Lancet. 2020; 395(10229): 1033-1034. PubMed Abstract | Publisher Full Text | Free Full Text

12. Paul G, Auwaerter MD: Johns Hopkins - Point of Care IT Guides. 2020. Reference Source

13. Warrington R, Watson W, Kim HL, et al:: An introduction to immunology and immunopathology. Allergy Asthma Clin Immunol. 2011; 7 Suppl 1(Suppl 1): S1. PubMed Abstract | Publisher Full Text | Free Full Text

14. Zhao J, Yuan $\mathrm{Q}$, Wang $\mathrm{H}$, et al:: Antibody responses to SARS-CoV-2 in patients of novel coronavirus disease 2019. Clin Infect Dis. 2020; ciaa344. PubMed Abstract | Publisher Full Text | Free Full Text

15. Pan $Y$, Zhang $D$, Yang $P$, et al: Viral load of SARS-CoV-2 in clinical samples. Lancet Infect Dis. 2020; 20(4): 411-412.

PubMed Abstract | Publisher Full Text | Free Full Text

16. Wang W, Xu Y, Gao R, et al.: Detection of SARS-CoV-2 in Different Types of Clinical Specimens. JAMA. 2020; 323(18): 1843-1844. PubMed Abstract | Publisher Full Text | Free Full Text

17. Guo L, Ren L, Yang S, et al:: Profiling Early Humoral Response to Diagnose Novel Coronavirus Disease (COVID-19). Clin Infect Dis. 2020; 71(15): 778-785. PubMed Abstract | Publisher Full Text | Free Full Text

18. Lan L, Xu D, Ye G, et al.: Positive RT-PCR Test Results in Patients Recovered from COVID-19. JAMA. 2020; 323(15): 1502-1503.

PubMed Abstract | Publisher Full Text | Free Full Text 


\section{Open Peer Review}

\section{Current Peer Review Status:}

\section{Version 1}

Reviewer Report 14 June 2022

https://doi.org/10.5256/f1000research.27484.r140766

(C) 2022 López Castro J. This is an open access peer review report distributed under the terms of the Creative Commons Attribution License, which permits unrestricted use, distribution, and reproduction in any medium, provided the original work is properly cited.

José López Castro

Monforte Public Hospital, Lugo, Spain

This is a clinical case of COVID19 that highlights the natural evolution of the disease and the possibility of diagnostic doubts, especially in the first days. It is well written but some issues need to be corrected:

- The introduction should be shortened and the amount of data provided, which are fairly well known, should be reduced.

The inflammatory potential of the disease should be explained and that this can make the symptomatology longer and more aggressive ( 2 bibliographic references are attached for this). ${ }^{1,2}$

The bibliography should be reviewed and updated.

Explain the different methods available for diagnosis of COVID19 and that the fact that an RT-PCR is positive after 14 days does not indicate that the disease is contagious.

After these modifications, I believe it can be indexed.

\section{References}

1. López Castro J: COVID-19 and thrombosis: Beyond a casual association.Med Clin (Engl Ed). 2020; 155 (1): 44 PubMed Abstract | Publisher Full Text

2. López Reboiro ML, Suárez Fuentetaja R, Gutiérrez López R, Ares Castro-Conde B, et al.: Role of lupus anticoagulant and von Willebrand factor in chronic reactive endotheliitis in COVID-19.J Infect. 82 (6): e27-e28 PubMed Abstract | Publisher Full Text

Is the background of the case's history and progression described in sufficient detail? Yes

Are enough details provided of any physical examination and diagnostic tests, treatment 


\author{
given and outcomes? \\ Yes
}

Is sufficient discussion included of the importance of the findings and their relevance to future understanding of disease processes, diagnosis or treatment?

Yes

Is the case presented with sufficient detail to be useful for other practitioners? Yes

Competing Interests: No competing interests were disclosed.

Reviewer Expertise: Epidemiology of heart failure in elderly population: risk factors, quality life health related and survival. Another line of research includes the study of prognostic biomarkers in COVID19 and genetics changes. Apart form this, we are developing a study about advance care planning financed by the Spanish Government.

I confirm that I have read this submission and believe that I have an appropriate level of expertise to confirm that it is of an acceptable scientific standard, however I have significant reservations, as outlined above.

Reviewer Report 15 February 2021

https://doi.org/10.5256/f1000research.27484.r78496

(C) 2021 Gao Y et al. This is an open access peer review report distributed under the terms of the Creative Commons Attribution License, which permits unrestricted use, distribution, and reproduction in any medium, provided the original work is properly cited.

\title{
Ya-Dong Gao
}

Department of Allergology, Zhongnan Hospital of Wuhan University, Wuhan, China

\section{Xiang Dong}

Zhongnan hospital of Wuhan University, Wuhan, China

This Case Report described a laboratory-confirmed COVID-19 patient in detail, with longitudinal and dynamic assessment. As the authors stated, several implications can be drawn from it. Firstly, false-negative results of virus nucleic acid testing can occur. In our previous retrospective study (Zhang et al., $2020^{1}$ ), 14.1\% of finally laboratory-confirmed COVID-19 patients had a negative initial RT-PCR test. This may result from various factors, such as human errors when following the diagnostic kit protocol, poor sensitivity of reagents, the site and method of specimen sampling and collection times, low viral load in the sampled area during the early phase, and so on. In addition, serological measurement of IgM and IgG antibodies against the virus can be a useful and complementary tool ( $\mathrm{Li}$ et al., 2020²). The patient in the report was tested both positive for IgM and IgG 16 days after the onset of symptoms, but the RT-PCR result at this time was not clarified in the text. Moreover, asymptomatic individuals can be infectious, and they were likely to get infected in a party. Therefore, social distancing and personal protective measures, e.g., 
wearing a mask, are important.

\section{References}

1. Zhang J, Cao Y, Dong X, Wang B, et al.: Distinct characteristics of COVID-19 patients with initial rRT-PCR-positive and rRT-PCR-negative results for SARS-CoV-2. Allergy. 2020; 75 (7): 1809-1812 Publisher Full Text

2. Li Z, Yi Y, Luo X, Xiong N, et al.: Development and clinical application of a rapid IgM-IgG combined antibody test for SARS-CoV-2 infection diagnosis.J Med Virol. 2020; 92 (9): 1518-1524 PubMed Abstract | Publisher Full Text

Is the background of the case's history and progression described in sufficient detail? Yes

Are enough details provided of any physical examination and diagnostic tests, treatment given and outcomes?

Yes

Is sufficient discussion included of the importance of the findings and their relevance to future understanding of disease processes, diagnosis or treatment?

Yes

Is the case presented with sufficient detail to be useful for other practitioners?

Yes

Competing Interests: No competing interests were disclosed.

Reviewer Expertise: Allergy.

We confirm that we have read this submission and believe that we have an appropriate level of expertise to confirm that it is of an acceptable scientific standard. 
The benefits of publishing with F1000Research:

- Your article is published within days, with no editorial bias

- You can publish traditional articles, null/negative results, case reports, data notes and more

- The peer review process is transparent and collaborative

- Your article is indexed in PubMed after passing peer review

- Dedicated customer support at every stage

For pre-submission enquiries, contact research@f1000.com 